\title{
THE RELATIONSHIP BETWEEN QUALITY OF WORK LIFE AND JOB MOTIVATION AMONG IRANIAN HIGH SCHOOL TEACHERS
}

\author{
ALI YASINI \\ ALIASGHAR HAYAT \\ Faculty of Education and Psychology \\ Kharazmi University, Iran \\ TAHEREH YASINI \\ Faculty of Education and Psychology \\ Chamran University of Ahvaz \\ AYATALLAH SAADATTALAB \\ Faculty of Education and Psychology \\ Shahid Behesti University
}

\begin{abstract}
This study examines the relationship between EFL teachers' quality of work life ( $Q W L)$ and their job motivation. 126 Iranian EFL teachers currently working in high schools of Tehran were administered two questionnaires that assessed their motivation and quality of work life. Participants' motivation to teach was assessed using a questionnaire developed by Noe \& Bachhuber (1990) which includes three major subscales: career insight (8 items), career identity (5 items), and career resilience (13 items). In addition this study used Walton's (1973) widely used quality of work life questionnaire. This 29-item questionnaire includes eight subscales: adequate and fair compensation (4 items), safe and healthy working (3 items), continued growth and security (3 items), constitutionalism in the work organization (5 items), the social relevance of work life (3 items), total life space (4 items), social integration in the work organization (4 items), and human progress capabilities (3 items). The results revealed that Iranian EFL teachers experience medium to low levels of motivation and QWL. In addition, a significant relationship was found between $Q W L$ categories and job motivation. Further, the best QWL predictors for teacher motivation were identified. The findings of this study are hoped to serve as a reference for principals and educational decision-makers in bringing about higher levels of motivation for language teachers.
\end{abstract}

Keywords: Teachers' motivation, quality of work life, EFL teachers.

\section{Introduction}

All of us have probably experienced times in our lives when we no longer can go on.
One turns into a wreck. There is no prospect of making future progress. This is most conspicuous in education. Teachers may feel this way at any point during their working 
life. When we tell our colleagues that we just couldn't face the thought of doing a particular task in class or getting down to preparing a lesson plan, we are describing our lack of motivation. The principal point then, would be to know what motivation is and how we can account for this phenomenon. In general, the concept of career motivation applies motivation theory to understanding career plans, behaviours and decisions. Many researchers have been theorizing about the content of career motivation and the association between career motivation, situational characteristics and behaviours (London, 1983). Pinder (1998), for instance, defines work motivation as a set of energetic forces that originate both within as well as beyond an individual's being, to initiate work-related behaviour, and to determine its form, direction, intensity, and duration. Similarly, London (1983) conceived career motivation as a multidimensional construct which includes three major domains: career resilience, career insight and career identity. Career resilience is the ability to adapt to changing circumstances. It includes welcoming job and organizational changes, looking forward to working with new and different people, having self-confidence and being willing to take risks. Career insight is the realism and clarity of the individual's career goals. It also involves having selfknowledge, specifically, knowing one's own strengths and weaknesses. Career identity is the degree to which people define themselves by their work and by the organization for which they work. It involves the degree to which they immerse themselves in activities related to their jobs and the organization, work hard, view themselves as professionals or technical experts and express pride in their employers. Noe and Bachhuber (1990) further clarify these terms. They define career identity as the direction of motivation, insight as the energizing or arousal component of motivation that encourages involvement in career planning and career decisions, and career resilience as the maintenance or persistence component. A closely-related issue to career motivation is the quality of work life. It refers to conditions and characteristics of work that contribute to motivation, performance and job satisfaction. The difference between the quality of work life and career motivation, then, seems to lie in the fact that quality of work life is a contributor to motivation. In other words, the higher the quality of work life, the more motivated employees will be. As Flippo (1998) mentions, quality of work life programmes include any improvements in the culture of the organization that will lead to employees' development and growth. Studies suggest that implementing such programmes will lead not only to a reduction in employee complaints and the number of absences from work but also an increasing level of optimism and cooperation in work-related issues. The concept of the quality of work life appeared near the end of the 60 s and according to Jean Pierre and Dupuis (2006) it encompassed a variety of theoretical concepts which aimed at counterbalancing the organizational problems. Walton (1973) was one of the first to propose an influential model for the quality of work life which is still widely applied today. He defined quality of work life as employees' reaction towards their jobs, especially the necessary consequences in satisfying their vocational needs and mental health. Luthans (1998) believes that the concept of the quality of work life has become an important social issue all around the world while over the previous decades the only focal issue was peoples' quality of personal lives. Today quality of work life is a dynamic multidimensional 
concept that includes such concepts as job security, rewarding systems, promotion opportunities, and involvement in decisionmaking processes. Akdere (2006) holds that researchers interested in the concept of the quality of work life are looking for new mechanisms to help the employees in order to balance their work and personal lives.

\section{Literature Review}

To illustrate the concept of motivation, as Dornyei (2001) states, psychologists have focused on two focal research traditions, namely motivational psychology which links behaviour to motives stemming from human mental processes (e.g. expectancy-value theories, self-determination theories, goal theories, etc.) and social psychology which looks at the action in the light of a broader social and interpersonal context, as reflected primarily by the individual's attitudes (e.g. the theory of reasoned action, the theory of planned behaviour, etc.). To account for this seemingly complex construct in the field of foreign/second language learning, previous research has followed the same tradition as in general psychology. Social psychology, in particular, was in the limelight when Robert Gardner (1972) proposed his influential motivation theory. Since then many studies were carried out, especially in the $90 \mathrm{~s}$ in relation to this theory and on the dichotomy of instrumental /integrative motivation with contradictory results(Oxford \& Shearin, 1994; Dornyei \& Otto, 1998; Dornyei, 2001). It was hoped that through these studies, teachers would be able to pinpoint efficient ways of motivating their own students. Motivational psychology components have also been the focus of many studies. Some, for example, have attended to value-expectancy related components (Clement, 1980; Ushioda, 1996 as cited in Dornyei, 2001) and many have tried to provide literature on the dichotomy of intrinsic V.S. extrinsic motivation following the main principles of the self-determination theory proposed by Deci and Ryan. However most, if not all, of the aforementioned studies in second/foreign language learning have focused on the concept of language learner motivation. Hence, the amount of past research on language teacher motivation (LTM) has been far too little relative to its importance. "There are very few studies discussing the nature of the motivation to teach. This seems, however, surprising since the teacher's level of enthusiasm and commitment is one of the most important factors that affect the learners' motivation to learn. Broadly speaking, if a teacher is motivated to teach, there is a good chance that his/her students will be motivated to learn", Dornyei (2001). On the other hand, there are some studies focusing on related issues such as teacher job satisfaction and then discussing the results under the label of motivation. This is, however, understandable since the two phenomena are inextricably linked through the influence each has on the other. Nadler and Lawler (1991, as cited in Dinham \& Scott, 1998) try to clarify the terms "career motivation" and "career satisfaction". Motivation is generally taken to mean a stimulus for behaviour and action in the light of a particular context, while satisfaction -and indeed dissatisfaction- is usually taken to mean a product of behaviour and action in the light of a particular context or environment. The question that preoccupied researchers in most of the studies on teacher motivation was to find the factors that influenced language teachers 'to do the job well' and not only 'to get the job done' (Johnson, 2000). This comes as no surprise as "with such a specific professional activity as teaching it might be realistic to 
expect to find certain unique motivational characteristics - for example, to identify some factors that have a special significance in terms of their impact on the motivation complex underlying teaching." (Dornyei, 2001, p.157). Freeman and Freeman (1994), for example, (as cited in Johnson, 2000) claimed that the exposure to new ideas, the availability of materials, the quality of colleagues and supervisors as well as the types of students they have are the factors that influence language teachers in their job. Similarly, Auerbach (1991) contended that 'alienation', as a demotivating state, occurs when some language teachers work more than one job for economic security and as a result they fail to sense themselves as being part of any one institution or group. Moreover, Crookes (1997) found that teachers' motivation is influenced by the fact that the curriculum and textbooks choices are mandated from authorities above or outside the institution because of the need to prepare students for standardized tests. Additionally, he claimed that another point that affects language teachers' motivation is the fact that they do not participate in decisionmaking concerning their own students. Similarly, Barrs (2005) classified some of the motivational factors identified by Pakistani teachers as potential dissatisfiers such as lack of resources to deliver adequate levels of training and follow-up and potential satisfiers such as monitoring and accountability systems. In addition, Butler (2007) tried to account for teacher motivation by adopting the goal-orientation theory as the theoretical framework. (A theory applied to study learner motivation hitherto). The study confirmed that mastery goals predicted positive perceptions of help-seeking, preferences for receiving autonomous help, and frequency of help-seeking; ability avoidance predicted negative perceptions and help avoidance; and work avoidance predicted expedient help seeking. These findings validated the proposed structure and measure of teacher-goal orientations. In a more recent study, Davidson (2007) conceived teacher motivation as a key factor that has been shown to affect the quality of education in Tanzania. At a basic level, he asserted, teacher motivation is linked to how teachers feel they are being treated and to the way they perceive their own living and learning conditions. The study calls for more concern for teachers and specifically improving teacher welfare. Finally, Ciani (2007) took a "top-down" approach by examining contextual elements of school-goal structure and teacher community on teachers' sense of self- and collective efficacy, and classroomgoal structures. Their results indicated that teachers in highly performance-oriented schools reported significantly less adaptive motivational beliefs, lower community, and more performance-oriented instruction than teachers in a low performance-oriented schools. Aside from career motivation, there has been a lot of research conducted in some organizations to deal with the quality of work life within the organization. Generally, the results suggest that the quality of work life has a positive relationship with the other variables within the organization such as performance, efficiency, job satisfaction and organizational commitment. (E.g. Spector, 1997; Cheng et al., 2007; Lu, 2007). However, there is a dearth of research when it comes to examining the quality of work life within educational organizations especially with regard to the specific discipline of language education. Day and his colleagues (2005), too, refer to that fact the relationship between teachers' motivation, efficacy, job satisfaction and commitment and between commitment and the quality of their work has not been the subject of extensive research. 
Noe and Bachhuber (1990) conceived career motivation as a multidimensional construct which includes three major domains: career resilience, career insight and career identity. What follows is a description of each domain:

1. Career identity: the degree to which people define themselves by their work and by the organization for which they work. It involves the degree to which they immerse themselves in activities related to their jobs and the organization, work hard, view themselves as professionals or technical experts and express pride in their employers.

2. Career insight: the realism and clarity of the individual's career goals. It also involves having self-knowledge, specifically, knowing one's own strengths and weaknesses.

3. Career resilience: the ability to adapt to changing circumstances. It includes welcoming job and organizational changes, looking forward to working with new and different people, having self-confidence and being willing to take risks.

Walton's (1973) model of the quality of work life was also applied in this study to analyse the status of Iranian EFL teachers' working conditions. Walton (1973) defined quality of work life as employees' reaction towards their jobs, especially the necessary conditions for satisfying their vocational needs and mental health. Accordingly, quality of work life emphasizes personal growth, working experience, and the ways to improve work in order to fulfil personal needs. Moorhed and Griffen (1998) delineate the model as including the following items: a. Adequate and fair compensation: equal payment for equal work and the balance between payment and social factors and also other kinds of work.

b. Safe and healthy working: creating physically immune working conditions and specifying rational working hours.

c. Opportunity for continued growth and security: creating groundwork to improve personal capabilities, opportunities to make use of what one has learned and make progress and assure employment and income.

d. Constitutionalism in the work organization: providing the groundwork for freedom of speech without being afraid of reaction from authorities and the dominance of rules and regulations over individuals.

e. The social relevance of work life: employees' perceptions about their social responsibility in the organization.

f. Total life space: making a balance between working life and other aspects of employees' life such as education, free time, and family life.

g. Social integration in the work organization: creating an atmosphere in which there is a sense of belonging to the organization by the employees.

h. Human progress capabilities: providing opportunities such as having independence and self-control, access to job-related information and various skills at work.

\section{Methodology}

For the purpose of this study, 6 districts from among the 22 educational districts of Tehran were selected via the cluster sampling 
procedure. Later, $126 \mathrm{EFL}$ teachers were randomly selected from among the high schools in these 6 districts to participate in the study.

Participants' motivation to teach was assessed using a questionnaire developed by Noe and Bachhuber (1990) which includes three major subscales: career insight (8 items), career identity ( 5 items), and career resilience (13 items). This 26-item questionnaire uses a 1 to 5 point scale showing the extent it corresponds to the participant's motivation to teach English. The overall reliability of the questionnaire was found to be 0.82 for the present study and context. In addition this study used Walton's (1973) widely used quality of work life questionnaire. This 29questionnaire includes eight subscales: adequate and fair compensation (4 items), safe and healthy working (3 items), continued growth and security (3 items), constitutionalism in the work organization

- (5 items), the social relevance of work life (3 items), total life space (4 items), social integration in the work organization (4 items), and human progress capabilities (3 items). This questionnaire, too, uses a 1 to 5 point scale to examine the quality of work life. The reliability of this questionnaire has been reported to be 0.926 where there was a chance for all EFL teachers of that district to get together. Before the questionnaire was administered, participants were provided with an explanation of the purpose of the study and assured that the results were solely for research purposes and would be treated as confidential.Eachquestionnairewas supposed to take 10 minutes to fill out. Participants were also encouraged to ask questions and seek clarifications if needed. After the teachers' responses to the questionnaires were codified, quantitative analyses were carried out on the acquired information. First of all, descriptive statistics were applied to describe Iranian EFL teachers' motivation and the quality of their work life. In addition, Pearson product moment correlation was conducted to compare job motivation aspects (Dependent variable) to the quality of work life factors (Independent variable). Finally a step by step regression was carried out to find the effects of the quality of work life factors on job motivation. The questionnaires were administered during in-service training sessions held by the educational office of each district. All the items were presented in Persian. The original English version of the items were translated into Persian and then back translated into English to ensure meaning equivalence across the two cultures. The two versions were evaluated by two education professors fluent in both languages and the best translated items were selected for inclusion. To ensure that the instruments were readily interpretable for Iranian teachers, pilot surveys were administered to a sample of secondary school teachers in Tehran. Data analysis was done in two levels of descriptive and inferential statistic approaches (frequencies, Pearson correlation and Stepwise regression test).

\section{Findings}

\section{Quality of Work Life}

Table 1 shows that the mean score for the quality of work life among the participants was 2.63 with a standard deviation of 0.39 . It amounted to saying that participants perceived themselves to have a medium to low level of quality of work life. The participants reported the highest level of quality of their work life in the category of social integration 
in the organization $(\mathrm{M}=3.75, \mathrm{SD}=.56)$ and the lowest level in the category of chance of growth and security $(\mathrm{M}=1.26, \mathrm{SD}=.68)$.

Teachers reported that their jobs offered very low chance of growth (career and personal) and security (job and wage), unfair and inappropriate compensation and undesirable work conditions (unhealthy physical environment). They felt there was no prospect for future progress in their jobs and that they had no chance of reviving this stagnant situation. In addition, they saw low levels of constitutionalism (little freedom of expression and few rights of protection) in their working environment. On the other hand, Iranian secondary school EFL teachers saw their jobs as desirable in at least two respects. First of all, teaching in secondary schools gave them an opportunity to balance the total space of their lives. In other words, they were able to allot enough time for leisure with their families, they were not forced to change geographically, and they see the schedules of the ministry of education as being stable. Secondly, they saw themselves as being socially integrated into the school community. They had good relations with their colleagues and they did not feel any prejudice against them.

Table 1

Descriptive Statistics for Quality of Work Life

\begin{tabular}{lcccc}
\hline Variables & N & Mean & SD & Level \\
\hline Fair and appropriate compensation & 126 & 1.37 & .57 & L \\
Work conditions & 126 & 2.94 & .49 & M-L \\
Chance of growth and security & 126 & 1.26 & .68 & L \\
Constitutionalism & 126 & 2.55 & .53 & M-L \\
Social relevance of work in life & 126 & 2.74 & .50 & M-L \\
Work and total space of life & 126 & 3.37 & .65 & M-H \\
Social integration in the Organization & 126 & 3.75 & .56 & M-H \\
Use and development of capacities & 126 & 2.66 & .61 & M-L \\
Total & 126 & 2.63 & .39 & M-L \\
\hline
\end{tabular}

Table 2

Descriptive Statistics for Career Motivation

\begin{tabular}{lcccc}
\hline Variable & $\mathrm{N}$ & Mean & SD & Level \\
\hline Career insight & 126 & 1.83 & .66 & $\mathrm{~L}$ \\
Career identity & 126 & 2.37 & .46 & $\mathrm{M}-\mathrm{L}$ \\
Career resilience & 126 & 2.90 & .42 & $\mathrm{M}-\mathrm{L}$ \\
Total & 126 & 2.23 & .32 & $\mathrm{M}-\mathrm{L}$ \\
\hline
\end{tabular}




\section{Career Motivation}

Table 2 displays the participants' perceptions on their motivation to teach. Overall, the participants perceived themselves to have medium to low level of job motivation $(\mathrm{M}=2.23, \mathrm{SD}=.32)$. They reported the highest level for the category of career resilience $(\mathrm{M}=2.90, \mathrm{SD}=.42)$ and the lowest level for career insight $(\mathrm{M}=1.83, \mathrm{SD}=.66)$. It seems that secondary school EFL teachers in the study did not have any specific career goals. They had been following the same teaching practice for a long time and they didn't feel any need to change or revise their goals. Although some of them attempted to keep abreast of developments in their fields, most of them did not find it necessary to keep current in their job affairs. That was why few of them have ever taken time to do the best possible work possible in the classroom.

\section{Correlation between QWL and CM}

It is found that there was a highly significant correlation between the categories of the quality of work life and career motivation and this was a positive direct relationship $(\mathrm{p}<.01, \mathrm{r}=.726)$. In other words, the more categories of the quality of work life were improved, the higher career motivation would be. However, the causality between quality of work life and career motivation was not defined. These results are depicted in Table 3.

\section{Table 3}

Correlation between Quality of Work Life and Motivation Categories

\begin{tabular}{lcc}
\hline & Career Motivation & \\
\cline { 2 - 2 } & Pearson correlation & Sig(2-tailed) \\
\hline Variable & & \\
Fair and appropriate compensation & $.51^{* *}$ & .004 \\
Work conditions & $.79^{* *}$ & .001 \\
Chance of growth and security & $.70^{* *}$ & .007 \\
Constitutionalism & $.53^{* *}$ & .003 \\
Social relevance of work in life & $.61^{* *}$ & .004 \\
Work and total space of life & $.78^{* *}$ & .001 \\
Social integration in the organization & $.66^{* *}$ & .001 \\
Use and development of capacities & $.84^{* *}$ & .002 \\
Total & $.72^{* *}$ & .002 \\
\hline
\end{tabular}

**. Correlations are significant at the 0.01 level (2-tailed).

Quality of Work Life Used to Predict Career Motivation

A stepwise multiple regression analysis was conducted to determine the most effective quality of work life predictors of career motivation. The eight categories of the quality of work life were specified as the independent variable (predictors), with the teachers' motivation as the dependent 
Table 4

Stepwise Regression: Quality of Work Life Categories to Predict Career Motivation

\begin{tabular}{cccccccc}
\hline Model & R & R Square & $\begin{array}{c}\text { Adjusted R } \\
\text { Square }\end{array}$ & $\begin{array}{c}\text { Std. Error of the } \\
\text { Estimate }\end{array}$ & Durbin-Watson & F & Sig. \\
\hline 1 & $.726 \mathrm{a}$ & .527 & .502 & .876 & 1.720 & 21.005 & .000 \\
\hline
\end{tabular}

a. Predictors: (Constant), Fair and appropriate compensation, Work conditions, Chance of growth and security, Constitutionalism, Social relevance of work in life, Work and total space of life, Social integration in the organization, Use and development of capacities

b. Dependent Variable: Career motivation

Table 5

Coefficients: Quality of Work Life Categories to Predict Career Motivation

\begin{tabular}{|c|c|c|c|c|c|c|c|c|}
\hline \multirow{2}{*}{\multicolumn{2}{|c|}{ Model }} & \multicolumn{2}{|c|}{$\begin{array}{l}\text { Unstandardized } \\
\text { Coefficients }\end{array}$} & \multirow{2}{*}{$\begin{array}{c}\text { Standardized } \\
\text { Coefficients } \\
\text { Beta }\end{array}$} & \multirow[t]{2}{*}{$\mathrm{t}$} & \multirow[t]{2}{*}{ Sig. } & \multicolumn{2}{|c|}{$\begin{array}{l}\text { Collinearity } \\
\text { Statistics }\end{array}$} \\
\hline & & B & Std. Error & & & & Tolerance & VIF \\
\hline \multirow[t]{9}{*}{1} & (Constant) & 1.14 & .419 & - & 2.72 & .007 & - & - \\
\hline & $\begin{array}{l}\text { Fair and appropriate } \\
\text { compensation }\end{array}$ & -.08 & .085 & .166 &.-94 & .345 & .637 & 1.57 \\
\hline & Work conditions & .029 & .067 & .107 & 1.44 & .032 & .843 & 1.18 \\
\hline & Chance of growth and security & .100 & .075 & .112 & 2.34 & .023 & .842 & 1.18 \\
\hline & Constitutionalism & -.02 & .072 & .111 & -.30 & .758 & .659 & 1.51 \\
\hline & Social relevance of work in life & 0.13 & .065 & .114 & .195 & .846 & .614 & 1.62 \\
\hline & Work and total space of life & .679 & .068 & .151 & .919 & .520 & .679 & 1.47 \\
\hline & $\begin{array}{l}\text { Social integration in the } \\
\text { organization }\end{array}$ & .048 & .077 & .186 & 2.63 & .000 & .592 & 1.69 \\
\hline & $\begin{array}{l}\text { Use and development of } \\
\text { capacities }\end{array}$ & .166 & .068 & .122 & 1.44 & .005 & .717 & 1.39 \\
\hline
\end{tabular}

a. Dependent Variable: Career motivation

variable (criterion). Preliminary analyses were conducted to examine the assumptions underlying a regression model. Test of Durbin-Watson amounted to 1.720 and since this score was within an acceptable range of 1.5 to 2.5 , it implied that multicollinearity considerations were met and we could make use of regression. As Tables 4 and 5 show, quality of work life categories were significantly correlated with career motivation $(\mathrm{F}(16,113)=21.005, \mathrm{p}=.000)$, with R $2=.527$ suggesting that $52 \%$ of 
variability in career motivation could be accounted for by categories of the quality of work life according to the regression model. The column standardized coefficients of Beta in Table 6 shows the sequence of factors affecting career motivation. The regression model implied that a combination of four of the quality of work life variables (work conditions, chance of growth and security, social integration in the organization, and the use and development of capacities) were significantly correlated with career motivation. The multiple regression analysis using the least square solution yielded the following equation:

$$
\begin{gathered}
Y=1.142+0.107\left(x_{1}\right)+0.112\left(x_{2}\right)+ \\
0.186\left(x_{3}\right)+0.122\left(x_{4}\right)
\end{gathered}
$$

Where $\mathrm{Y}$ represents the predicted career motivation, $x_{1}$ refers to work conditions, $x_{2}$ refers to chance of growth and security, $x_{3}$ refers to social integration in the organization and $\mathrm{x}_{4}$ is the use and development of capacities.

\section{Discussion and Conclusion}

This study sets out to develop a thorough understanding of the quality of work life and motivation of Iranian high school EFL teachers. Several findings were generated from the results. First of all, Iranian high school EFL teachers perceived themselves to have a medium to low level of quality of work life. In other words, they perceived that their jobs offered unfair and inappropriate compensation, undesirable work conditions, very low chance of career and personal growth, low job security and constitutionalism, irrelevance in life and not developing their full capacities. Low and unfair payment has always been a great concern for teachers in Iran. Teachers feel that they are not paid what they deserve. Most of them are forced to work longer extra hours (sometimes for more than 48 hours a week) to be able to afford their family life. This will obviously have a negative effect on the quality of the work they do. However, it should be noted that although there is a significant correlation between all of the factors of the quality of work life and career motivation, the relationship between fair and appropriate compensation and career motivation is not that high. Oshagbemi (1997) contends that in spite of the popular belief that high salaries and productivity profits are the main reasons for creating motivation, they should only be looked upon as maintenance factors so as to ensure that employees are not dissatisfied. In addition, Bandura (1977) holds that the intrinsic motivation from self-evaluation is more effective than the extrinsic reinforcement given by others. Therefore, it seems to be a misunderstanding among the public that high salaries and productivity profits are the main reasons for creating motivation though they play an important role in satisfying the teachers and eliminating the need to work extra hours or adopt second jobs. In addition, EFL teachers experience undesirable work conditions. The physical environments in most high schools in Iran are unhealthy and not safe. Overcrowded classes and lack of up-to-date facilities may play a role in exacerbating the situation. However, in spite of the above mentioned difficulties, teachers rated the lowest level for the category of chance of growth and security. They felt that there was no prospect for future progress in their jobs and that they had no chance of changing this stagnant situation. Some teachers have been spending years teaching the same stuff with the same approach. They seem to have become fossilized in this regard. The most important concern for teachers then, is to have the opportunity to work at their goals and feel purposeful, thereby reaching the 
highest levels of their performance. Other issues that EFL teachers seem to complain about is that of the constitutionalism and social irrelevance of their jobs. EFL teachers feel their organization is not responsible for students' achievement and that they are not given the autonomy to make their own decisions. Education authorities and school principals usually expect teachers to follow fixed procedures in their teaching. Textbooks are mandated from the ministry of education and teachers are expected to cover the material within the given time constraints. Teachers lack freedom of speech since they are afraid of reaction from the authorities. However Iranian high school EFL teachers enjoy their jobs in at least two respects. Firstly they have an opportunity to balance the total space of their lives. In other words, they have time for leisure with their families and they are not forced to change geographically. This is most probably due to the large number of holidays in the educational system of Iran and the conservative approach of the ministry of education towards the educational system. Secondly, teachers see themselves as being socially integrated into the school community. They have good relations with their colleagues and they don't feel any prejudice against each other and this is what they consider a desirable feature of their working environment. Another finding of the study implies that the participants perceived themselves to have medium to low level of job motivation suggesting that they have low career insight, identity and resilience. Therefore, Iranian EFL teachers don't feel the need to have specific goals, revise their current practice and/or keep up-to-date with new developments in their careers. Insight is very low among the participants since their goals are not clear to them. Having to deal with the same stuff for years obviates the need for them to consider their own strengths and weaknesses. It may also be that there is no formal mechanism for intercommunication between the teachers and the authorities. Identity, too, is low among the participants. In other words, Iranian EFL teachers do not immerse themselves in activities related to their jobs and the organization. Lack of self-image as professionals or technical experts hinders hard work hence they don't express pride in the work they do. Low levels of resilience -the ability to adapt to changing circumstances-implies not welcoming change, low self-confidence and an unwillingness to take risks. Finally, the study found a strong correlation between quality of work life and career motivation. Therefore, in order to heighten the motivation of teachers in creating high quality working conditions becomes crucially important. A combination of four of the quality of work life variables (work conditions, chance of growth and security, social integration in the organization, and the use and development of capacities) were significantly correlated with career motivation. Therefore it can be concluded that these factors are stimulating and result in higher levels of teacher motivation. In other words, for teachers to be motivated, aside from improving their work conditions, groundwork should be laid so that they feel they are capable of realizing their potentials and conditions created in which they can practically make progress.

The present study has important implications for Iranian EFL teachers on matters important to their profession and can act as a guide to educational decision-makers in Iran. Authorities in the ministry of education should be aware of the influence of these factors on teachers' motivation. They should know that financial incentives will not suffice in bringing about motivation for teachers, rather they should make their best to improve working conditions, encourage social integration within and between 
schools, and use and develop teachers' capacities in such a way that they feel they are constantly growing. A few limitations, however, will need to be taken into account when interpreting the results. Firstly, the study only investigated the quality of work life, career motivation, and the relationship between them. More studies need to be conducted to find out the other factors that affect the motivation to teach. Secondly, the participants were from the capital city of Tehran only. Thus, to be able to generalize the results to a wider population, a larger scope of subjects should be included for future study.

\section{References}

Akdere, M. (2006). Improving quality of work life: Implications for human resources. Business Review, 1, 173187.

Auerbach, E. R. (1991). Politics, pedagogy, and professionalism: Challenging marginalization in ESL. College ESL, 1(1), 1-9.

Barrs, J. (2005). Factors contributed by community organizations to the motivation of teachers in rural Punjab, Pakistan, and implications for the quality of teaching. International Journal of Educational Development, 25(3), 333-348.

Butler, R.(2007). Teachers' achievement goal orientations and associations with teachers' help seeking: Examination of a novel approach to teacher motivation. Journal of Educational Psychology, 99(2), 241-257.

Cheng, P. F., Yu Fang, Y., Liang Chin, H., \& Ingchung, H. (2007). A study on motivation employees learning commitment in the post downsizing era: Job satisfaction perspective.
Journal of World Business, 42, 121136.

Ciani, D. K., Summers, J., \& Easter, M. (2007). A "top-down" analysis of high school teacher motivation. Contemporary Educational Psychology.

Crookes, G. (1997). What influences what and how second and foreign language teachers teach? Modern Language Journal, 81(1), 67-79.

Davidson, E. (2007). The pivotal role of teacher motivation in Tanzanian education. The Educational Forum, 71(2), 157-166.

Day, C., Elliot, B., \& Kington, A. (2005). Reform, standards and teacher identity: Challenges of sustaining commitment. Teaching and Teacher Education, 21(5), 563-577.

Dinham, S., \& Scott, C. (1998). A three domain model of teacher and school executive career satisfaction.Journal of Educational Administration, 36(4), 362-376.

Dornyei, Z. (1994). Motivation and motivating in the foreign language classroom. The Modern Language Journal, 78(3), 273-284

Dornyei,Z.(2001).Teaching and researching motivation. London: Pearson Education.

Dornyei, Z., \& Otto, I. (1998). Motivation in action: A process model of L2 motivation. Working Papers in Applied Linguistics, 4, 43-69.

Flippo, E. B. (1998). Personal Management. Auckland: McGraw-Hill.

Gardner, R.C., \& Lambert, W. E. (1972). Attitudes and motivation: Second language learning. London: Newbury House.

Johnson, C. (2001). Factors influencing motivation and de-motivation in Mexican EFL teachers. MEXTESOL Journal, 26(2), 55-69. 
Jean, P. M., \& Dupuis, G. (2006). Quality of work life: Theoretical and methodological problems, and presentation of new model and instrument. Social indicators research, 11 .

London, M. (1983). Toward a theory of career motivation.Academy of Management Review, 8(4), 620-630.

Luthans, F. (1998). Organizational behavior. Mc Graw-Hill.

Moorhed, G., \& Griffin, R. (1998). Organizational behavior. Boston: Hougton Mifflin.

Noe, R. A., Noe, A. W., \& Bachhuber, J. A. (1990). An investigation of the correlates of career motivation. Journal of Vocational Behavior, 37, 340-356.

Oshagbemi, T. (1997). Job satisfaction and dissatisfaction in higher education. Journal of Education and Training, 39.

Oxford, R. L., \& Shearin, J. (1994). Language learning motivation: Expanding the theoretical framework. The Modern Language Journal, 78, 12-28.

Spector, P. E. (1997). Job satisfaction. New Delhi: Sage publications.

Walton, R. E. (1973). Quality of work life: What is it? Sloan Management Review Journal, 3, 11-21. 


$$
\begin{aligned}
& \text { हृ } \\
& \text { (1) } \\
& \frac{\varepsilon}{5} \\
& \bar{\varepsilon} \\
& \varepsilon \\
& E \\
& \frac{0}{ \pm}
\end{aligned}
$$

